\title{
Les craniosynostoses héréditaires. Une première lésion moléculaire dans un gène à domaine homéo
}

La craniosynostose consiste en une fusion prématurée des sutures crâniennes. Elle survient chez environ 1 pour 3000 enfants. Elle provoque une déformation du crâne, et peut être associée ou non à d'autres malformations, en particulier des syndactylies. On en a décrit près d'une centaine de types différents, dont la moitié a une origine génétique, chiffre peut-être surestimé car incluant probablement des syndromes alléliques. Ces syndromes sont d'hérédité monogénique et le plus souvent autosomiques dominants. Les plus courants n'ont pas encore de mécanisme génétique connu, mais quelques-uns ont une localisation chromosomique de leur gène identifiée. Et, sous forme de première, l'un deux vient d'avoir sa lésion moléculaire reconnue [1] par une équipe américaine (12 auteurs). Elle a choisi l'approche des gènes candidats, en étudiant des gènes de contrôle du développement connus pour jouer un rôle dans la morphogenèse cranio-faciale. Parmi ces candidats potentiels, figurent des gènes codant pour des protéines qui sont des régulateurs transcriptionnels intervenant dans le développement, et qui sont porteurs d'un domaine de 60 acides aminés, dit domaine homéo, très conservé dans l'évolution [2]. Un de ces gènes, MSX2 (appelé aussi HOX8.1) a pu être localisé sur le chromosome 5. Or, dans la région distale du bras long du chromosome 5 , en $5 \mathrm{q} 35$, avait pu être fixé le locus d'une forme particulière de craniosynostose, le type Boston, dans une famille très étendue suivie sur trois générations [3]. Cette condition a une pénétrance élevée, mais une expression variable, en gravité et quant aux modalités des déformations. Le travail de Jabs et al. [1] a exigé le clonage du gène MSX2 humain et son analyse. Il a été facilité par la connaissance antérieure de gènes $m s x 2$ de plusieurs espèces, particulièrement celui de la souris [4] ; ce dernier est formé de deux exons séparés par un intron. Le premier exon code pour 127 acides aminés, domaine supposé d'activation; le second code pour 126 acides aminés, comprenant le domaine homéo et une portion Cterminale. En partant du premier exon du gène de la souris, on a obtenu les exons du gène humain; les protéines des deux espèces ont entre elles une similitude de $92 \%$. Pour obtenir la preuve d'une liaison entre MSX2 et la maladie, on utilisa un polymorphisme de longueur d'un dinucléotide GT. La ségrégation du marqueur avec les symptômes de la craniosynostose se fit, sans aucun recombinant (lod score 4,80) (voir définition du lod score dans $m / s n^{\circ} 12$, vol. 9, p. 1418). La recherche de mutation dans la partie codante se fit par séquençage des deux exons chez des membres atteints et indemnes de la famille à risque. Une mutation fauxsens fut détectée chez les malades : un changement $C \rightarrow A$ au nucléotide 64 de l'exon 2, entraînait le remplacement d'une proline par une histidine au codon 7 du domaine homéo, à l'état hétérozygote. A l'aide d'oligonucléotides spécifiques, on put alors cribler la famille, et montrer que la mutation était présente chez les treize sujets affectés, absente chez dix membres indemnes de la famille et chez cent témoins. L'acide aminé Pro7 du domaine homéo est invariant au cours de l'évolution, depuis la drosophile et l'oursin. Par ailleurs, l'expression du gène MSX2 au cours du développement est en accord avec l'hypothèse d'une altération de son fonctionnement ayant des conséquences fâcheuses sur l'ossification. Il restera toutefois à démontrer, par inactivation du gène ou par transgénèse, que le gène MSX2 joue effectivement un rôle dans ces processus de développement. Cete observation est restée unique jusqu'à présent. Les tentatives des auteurs pour chercher une anomalie de MSX2 dans des syndromes voisins sont restées vaines.

Les études faites sur d'autres variétés de craniosynostoses sont moins avancées mais leurs résultats ne sont pas négligeables : deux syndromes, probablement différents, ont été rapportés au bras court du chromosome 7, en deux régions apparemment distinctes; le gène du rare syndrome de Greig (céphalopolysyndactylie) a pu être fixé avec précision en 7 pl 3 car il est associé à une interruption par translocation du gène GL13 à doigt de zinc [5]; plus distale (en 7p21) semble être la position d'un gène d'une forme d'acrocéphalosyndactylie, dite syndrome de SaethreChotzen [6]. Cette forme est distincte de la plus courante, le syndrome d'Apert, dont la génétique n’a pas encore été précisée.

L'énumération de ces travaux montre qu'ils n'en sont encore qu'à leurs débuts, mais que leur évolution permet d'espérer en obtenir bientôt une vue d'ensemble.

J.C.D.

1. Jabs EW, Muller U, Li X, et al. A mutation in the homeodomain of the human MSX2 gene in a family affected with autosomal dominant craniosynostosis. Cell 1993; 75 : 44.3-50

2. McGinnis W', Krumlauf R. Homeobox genes and axial patterning. Cell 1992; 68: 283-302.

3. Muller U, Warman ML, Mulliken JB, Weber JM. Assignment of a gene locus involved in craniosynostosis to chromosome 5qter Hum Mol Genet 1993; 2: 119-22.

4. Bell JR, Noveen A, Liu YH, et al. Genomic structure, chromosomal location, and evolution of the mouse Hox 8 gene. Genomics $1993 ; 16: 123-31$.

5. Vortkamp A, Gessler M, Grzeschik KH GL13 zinc finger gene interrupted by translocations in Greig syndrome families. Nature $1991 ; 352: 539-40$

6. Brueton LA, van Herwerden L, Chotai KA, Winter RM. The mapping of a gene for craniosynostosis: evidence for linkage of the Seathre-Chotzen syndrome to distal chromosome 7p. I Med Genet 1992; 29: 681-5.
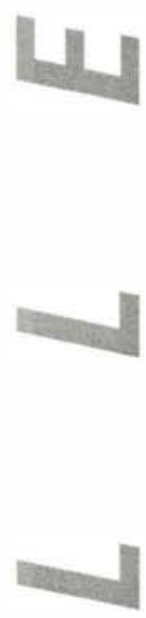